\title{
Discordance between Hip and Spine Bone Mineral Density: A Point of Care
}

\author{
Byung-Ho Yoon', Deog-Yoon Kim² \\ 'Department of Orthopedic Surgery, Ewha Womans University, College of Medicine, Mokdong Hospital, Seoul; \\ ${ }^{2}$ Department of Nuclear Medicine, Kyung Hee University Hospital, Kyung Hee University School of Medicine, Seoul, Korea
}

\author{
Corresponding author \\ Deog-Yoon Kim \\ Department of Nuclear Medicine, Kyung Hee \\ University Hospital, Kyung Hee University \\ School of Medicine, 23 Kyungheedae-ro, \\ Dongdaemun-gu, Seoul 02447, Korea \\ Tel: +82-2-958-8211 \\ Fax: +82-2-968-1848 \\ E-mail: ksbmr@naver.com
}

Received: November 9, 2021

Revised: November 16, 2021

Accepted: November 17, 2021
Copyright $(\complement 2021$ The Korean Society for Bone and Mineral Research

This is an Open Access article distributed under the terms of the Creative Commons Attribution Non-Commercial License (https://creativecommons.org/licenses/by-nc/4.0/) which permits unrestricted non-commercial use, distribution, and reproduction in any medium, provided the original work is properly cited.

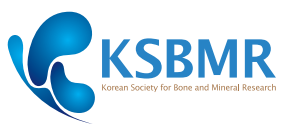

Dual energy X-ray absorptiometry (DXA) is the most commonly used and validated method for the determination of bone mineral density (BMD).[1] DXA is usually measured at the central bone (hip and spine) and the BMD is determined by the lowest score at 1 of these 2 sites.[1,2] Discordance is defined as a discrepancy in the BMD measurements at the 2 sites, which can pose clinicians with the predicament on how to incorporate BMD measurement when deciding on the diagnosis and management of postmenopausal osteoporosis. Since its introduction in 2000, the World Health Organization has developed a classification system;[3] minor discordance indicates osteopenia at one site and normal or osteoporotic $\mathrm{BMD}$ at another, whereas major discordance indicates normal bone density at 1 site and osteoporosis at another.[4] T-score discordance can occur for a variety of reasons related to physiologic and pathologic patient factors as well as the performance or analysis of DXA itself.

The prevalence of spine-hip T-score differences owing to minor discordance has been reported in $38 \%$ to $51 \%$ of patients examined with DXA; otherwise, less than $5 \%$ of patients examined with DXA show major discordance.[5-9] Discordance was found to be significantly higher in the elderly group, with 2 patterns stratified by age.

In women aged 50 to 60 years with menopause $>3$ years, lower T-scores are more easily found in the spine than in the hip.[10] The differential bone loss among bones in the body and the proportion of cortical and cancellous bones have played a role in BMD discordance; cancellous bone has a higher rate of bone turnover and is lost earlier than cortical bone, suggesting that the presence of more cancellous bone in the spine might account for earlier loss of bone matrix in early osteopenia and more significant discrepancy in late osteoporosis.[11]

On the other hand, older age ( $>70$ years) has been positively associated with a higher T-score in the spine than in the hip,[10-12] mainly caused by degenerative changes such as vertebral osteophytosis/endplate and facet sclerosis, aortic calcification, syndesmophytes, and vertebral compression deformity.[8,13] An increasing relative proportion of clinical vertebral fracture to hip fracture was seen for increasing spine-hip T-score discordance in women aged 50 to 64 years and women aged $\geq 65$ years. 
BMD might not fully capture the osteoporotic fracture risk because many fragility fractures in postmenopausal women occur with osteopenia and not osteoporosis.[14] Also, physicians often need to define populations at high risk for fracture when making treatment decisions for postmenopausal patients with T-scores in the osteopenic range. $[14,15]$ Thus, the fracture risk assessment tool (FRAX) has been developed to evaluate future fracture risk and avoid missing the opportunity to prevent fractures. However, FRAX may underestimate the risk of major osteoporotic fracture when the lumbar spine T-score is much lower ( $>1$ standard deviation discrepancy) than the femoral neck Tscore. $[8,10]$ Since only hip BMD is included in the FRAX calculation, other BMD measurement sites are not currently a component of FRAX. As a result, the risk of other osteoporotic fractures, compared to hip fractures, has often been underestimated in clinical practice. $[8,10,15]$

If patients are left untreated for osteoporosis, their bone density will increase rapidly. Hence, early identification and treatment are key to preventing offset (difference) between the lumbar spine and femoral neck T-scores.[10,16,17] In light of these results, the 2010 Osteoporosis Canada guidelines state that pharmacotherapy may be considered in individuals with a moderate risk for fracture and a lumbar spine T-score much lower than the femoral neck T-score. [18] Other studies suggest that major discordance or discordance of more than -1.5, are associated with an increased risk of fracture; therefore, aggressive osteoporosis treatment should be considered. $[5,9,19]$

To date, there are limited data regarding the effectiveness of osteoporosis treatments to lower fracture risk in osteopenia patients with discordance. Therefore, further prospective multicenter studies are needed to validate the performance of early interventions in various categories of these patients.

Clinicians and densitometrists should expect more than $40 \%$ of women screened for DXA to have T-score discordance between the spine and hip. Counseling patients for osteoporosis by taking into account T-score discordance, can enhance compliance and optimize the management of osteoporosis. Recognition of this issue may also play an additional role in making clinical decisions and minimizing the future risk of osteoporotic fractures.

\section{DECLARATIONS}

\section{Conflict of interest}

No potential conflict of interest relevant to this article was reported.

\section{ORCID}

Byung-Ho Yoon https://orcid.org/0000-0001-8518-6331

Deog-Yoon Kim https://orcid.org/0000-0003-4054-0231

\section{REFERENCES}

1. Blake GM, Fogelman I. The role of DXA bone density scans in the diagnosis and treatment of osteoporosis. Postgrad Med J 2007;83:509-17. https://doi.org/10.1136/pgmj.2007. 057505.

2. Kanis JA, Harvey NC, McCloskey E, et al. Algorithm for the management of patients at low, high and very high risk of osteoporotic fractures. Osteoporos Int 2020;31:1-12. https: //doi.org/10.1007/s00198-019-05176-3.

3. Woodson G. Dual X-ray absorptiometry T-score concordance and discordance between the hip and spine measurement sites. J Clin Densitom 2000;3:319-24. https:// doi.org/10.1385/jcd:3:4:319.

4. Faulkner KG, von Stetten E, Miller P. Discordance in patient classification using T-scores. J Clin Densitom 1999;2:34350. https://doi.org/10.1385/jcd:2:3:343.

5. Lee KJ, Min BW, Song KS, et al. T-score discordance of bone mineral density in patients with atypical femoral fracture. J Bone Joint Surg Am 2017;99:1683-8. https://doi.org/10. 2106/jbjs.16.01440.

6. Younes M, Ben Hammouda S, Jguirim M, et al. Discordance between spine and hip Bone Mineral Density measurement using DXA in osteoporosis diagnosis: prevalence and risk factors. Tunis Med 2014;92:1-5.

7. Singh M, Magon N, Singh T. Major and minor discordance in the diagnosis of postmenopausal osteoporosis among Indian women using hip and spine dual-energy X-ray absorptiometry. J Midlife Health 2012;3:76-80. https://doi. org/10.4103/0976-7800.104457.

8. Leslie WD, Lix LM, Johansson $\mathrm{H}$, et al. Spine-hip discordance and fracture risk assessment: a physician-friendly FRAX enhancement. Osteoporos Int 2011;22:839-47. https: //doi.org/10.1007/s00198-010-1461-5.

9. Xu XM, Li N, Li K, et al. Discordance in diagnosis of osteo- 
porosis by quantitative computed tomography and dualenergy X-ray absorptiometry in Chinese elderly men. J Orthop Translat 2019;18:59-64. https://doi.org/10.1016/j.jot. 2018.11.003.

10. Seok H, Kim KJ, Kim KM, et al. High prevalence of spinefemur bone mineral density discordance and comparison of vertebral fracture risk assessment using femoral neck and lumbar spine bone density in Korean patients. J Bone Miner Metab 2014;32:405-10. https://doi.org/10.1007/ s00774-013-0512-3.

11. El Maghraoui A, Mouinga Abayi DA, Ghozlani I, et al. Prevalence and risk factors of discordance in diagnosis of osteoporosis using spine and hip bone densitometry. Ann Rheum Dis 2007;66:271-2. https://doi.org/10.1136/ard. 2006.062372.

12. Chan CY, Subramaniam S, Mohamed N, et al. Prevalence and factors of T-score discordance between hip and spine among middle-aged and elderly Malaysians. Arch Osteoporos 2020;15:142. https://doi.org/10.1007/s11657-02000821-5.

13. Hong AR, Kim JH, Lee JH, et al. Metabolic characteristics of subjects with spine-femur bone mineral density discordances: the Korean National Health and Nutrition Examination Survey (KNHANES 2008-2011). J Bone Miner Metab 2019;37:835-43. https://doi.org/10.1007/s00774-018-0980-6.

14. Siris ES, Miller PD, Barrett-Connor E, et al. Identification and fracture outcomes of undiagnosed low bone mineral density in postmenopausal women: results from the National Osteoporosis Risk Assessment. JAMA 2001;286:281522. https://doi.org/10.1001/jama.286.22.2815.

15. Leslie WD, Morin SN, Lix LM, et al. Impact of spine-hip discordance on fracture risk assessment and treatment qualification in Canada: the Manitoba BMD registry. Arch Osteoporos 2020;15:85. https://doi.org/10.1007/s11657-02000763-y.

16. Johansson H, Kanis JA, Odén A, et al. Impact of femoral neck and lumbar spine BMD discordances on FRAX probabilities in women: a meta-analysis of international cohorts. Calcif Tissue Int 2014;95:428-35. https://doi.org/10.1007/ s00223-014-9911-2.

17. Moayyeri A, Soltani A, Tabari NK, et al. Discordance in diagnosis of osteoporosis using spine and hip bone densitometry. BMC Endocr Disord 2005;5:3. https://doi.org/10.1186/ 1472-6823-5-3.

18. Lentle B, Cheung AM, Hanley DA, et al. Osteoporosis Canada 2010 guidelines for the assessment of fracture risk. Can Assoc Radiol J 2011;62:243-50. https://doi.org/10.1016/ j.carj.2011.05.001.

19. Zhu K, Hunter M, James A, et al. Discordance between fat mass index and body mass index is associated with reduced bone mineral density in women but not in men: the Busselton Healthy Ageing Study. Osteoporos Int 2017; 28:259-68. https://doi.org/10.1007/s00198-016-3710-8. 
